\title{
Electric Vehicle Use in Public Fleets: The Case of the Genoa University
}

\author{
Federica Foiadelli, Michela Longo \\ Dipartimento di Energia \\ Politecnico di Milano \\ Milan, Italy \\ michela.longo@polimi.it
}

\author{
Federico Delfino, Stefano Bracco \\ Department of Naval, Electrical, \\ Electronic and Telecommunication \\ Engineering - DITEN \\ University of Genoa - Savona \\ Campus, Via Magliotto 2, Savona - \\ Italy \\ stefano.bracco@unige.it
}

\author{
Domenico Spina, Tom Dhaene \\ IDLab, Department of Information \\ Technology, Ghent University-imec, \\ Ghent, Belgium \\ domenico.spina@ugent.be;
}

\begin{abstract}
Electric mobility is assuming a central role in the new world energy scenario where Renewable Energy Sources (RES) have increased their contribution to the electricity production, mainly due to the fact they are characterized by a reduced environmental impact; in the aforesaid context, Electric Vehicles (EVs) can play a significant role to facilitate the integration of RES into the power grid, also within smart grid infrastructures. Public administration represents one of the sectors that can mostly benefit from the use of the EV technology in its fleets; in many countries governments have introduced incentive policies to support the spread of the electric mobility and car manufacturers are developing EVs for urban transportation users. In this paper, the attention is focused on a smart microgrid project developed at the University of Genoa and based on the integration of RES, EVs and storage systems. In particular, the attention is here pointed on the use of the EVs to highlight the different habits of recharge adopted at the Genoa University. The paper describes the smart microgrid test-bed facility at the Savona Campus and reports the most significant results relative to an experimental campaign conducted on EVs.
\end{abstract}

Index Terms--electric vehicles; smart microgrids; electrical storage systems; renewable energy sources; modeling.

\section{INTRODUCTION}

As highlighted by the European Commission, the development of the transport sector represents a central issue in today's economy and society, considering that it is important to assess its influence on growth and employment [1-3]. The transport sector employs around 10 million people and about $13 \%$ of every household's budget is related to transport goods and services; a reliable and efficient transport system can foster employment, but it has to be characterized by a low environmental impact. With regard to the aforementioned aspect, as described in [4], the European Union heavily depends on fossil fuels in the transport sector; oil-based fuels represent more than $95 \%$ of the sector's primary energy consumption. The EU's environmental policy tends to a global shift towards a low-carbon scenario characterized by low-emission mobility; the reduction of $\mathrm{CO}_{2}$ emissions in the transport sector can determine global benefits, considering that carbon dioxide emissions due to transport are at least $20 \%$ of the EU's greenhouse gas emissions [4]. Electric mobility is assuming more and more importance, and nowadays manufacturers are particularly active in reducing capital costs of Electric Vehicles (EVs) and charging infrastructures. Moreover, European governments are promoting electric mobility through the adoption of incentive policies and other benefits, related on both the demand and supply parts; the reduction of emissions (mainly represented by $\mathrm{CO} 2$ and nitrogen oxides) is a leading goal, but economic and technical aspects have also to be taken into account [5]. Apart from emissions, EVs reduce noise, fuel and maintenance costs as there are fewer moving parts in EVs than in internal combustion engine (ICE) vehicles; despite these advantages, the market is slow to adopt EVs because of the relatively high purchase price of EVs, limited battery range, and insufficient battery-charging infrastructure [6]. As highlighted in [7], one of the key barriers to increasing emobility is the fact that the business models have yet to be fully developed and, especially in the early years, car-sharing schemes played an important role to initiate the deployment of EV in some EU member states [8].

In the recent years, there have been important efforts to study the effects of strategies to reduce on-road traffic emissions and the consequent effects of these emissions on air quality. The European Commission has identified three priority areas for action: increasing the efficiency of the transport system (with the use of digital technologies and smart pricing); speeding up the deployment of low-emission alternative energy for transport and removing obstacles to the electrification of transport; moving towards zero-emission vehicles [9-11]. In the scenario described, in order to overcome the market uptake barriers and encourage more consumers to buy electric vehicles, state and local governments in many countries have adopted subsidy 
programs as well as proposed new policies: financial incentives, tax relief, toll-fee exemption, free parking, and free recharging stations, etc. [12]. As reported in [13], more measured policy mechanisms to promote increased uptake of EVs could include educational programs and fleet trial programs to raise awareness of EV performance, supporting car share schemes that utilize EV technologies, reducing or removing taxes on the import of EVs, or providing EVs with access to restricted transit lanes. On the other hand, EVs have some limits in terms of battery capacity and driving range, this last being also influenced by the driving style [14]. As a consequence, EVs are considered the best solution for urban and suburban driving, also considering that especially in urban traffic, characterized by a lot of accelerating and braking, EVs are very energy efficient and make an important contribution to air pollution control [15]; but it is important to consider that an uncoordinated charging of EVs can cause a severe stress on the power grid. Above all, public administrations can benefit from the use of EVs through the appropriate use of the procurement process, local authorities can support the uptake of EVs through the direct purchase of vehicles in their own fleets or as a requirement for their suppliers.

The goal of this study is to present a smart microgrid project developed at the Savona Campus of the Genoa University, in Italy, with a focus on the use of the EVs and their integration with Renewable Energy Sources, especially photovoltaic system (PV). In particular, different habits for the vehicles charging are analyzed and new scenarios taking advantage from the full potentiality of the smart mobility are studied.

\section{THE CASE STUDY}

A real test-case has been studied: the Smart Polygeneration Microgrid (SPM) of the Savona University Campus (Figure 1), in Italy [16], where renewable power plants and EVs charging infrastructures are installed. The SPM is owned by the University of Genoa and is operative since the beginning of 2014, within the framework of the "Energia 2020" project.

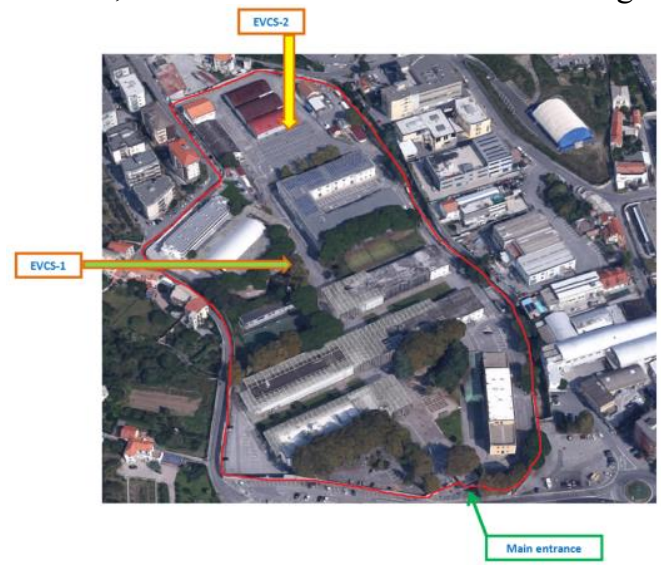

Figure 1. The map of the Savona Campus.

The "Energia 2020" project aims at transforming the Savona Campus into a test-bed facility where it is possible to test the technologies of the smart city. The project is composed of the following three projects: Smart Polygeneration Microgrid
(SPM), Smart Energy Building (SEB) and Energy Efficiency Measures (EEM). In particular, the SPM project, on which the attention is here focused, has been funded by the Italian Ministry of Education, University and Research (MIUR) and has permitted to build a smart electrical and thermal microgrid that is used to satisfy the energy needs of the Savona Campus. The second phase of the "Energia 2020" project has led to the construction of the SEB (co-funded by Italian Ministry of Environment and Protection of Land and Sea) which is a ZEB building directly connected to the SPM, equipped with photovoltaic and thermal solar plants and a geothermal heat pump, and managed by an innovative BMS (Building Management System) integrated within the EMS (Energy Management System) of the SPM, this last including control and optimization strategies for consumptions forecasting, operations planning and real time control of the grid [17-19]. Finally, it is important to mention the Smart City Demo Campus project, developed in collaboration with Enel SpA, to make the Campus a pilot site where the state-ofthe-art technologies for the City of the Future (digital City iper-connected, City secure, health \& wellness for the Citizens) could be tested.

The research activities at SPM are mainly focused on:

- planning and design of smart microgrids for smart cities;

- development of Energy Management Platforms for different grid-size applications (nanogrids, microgrids) and different usage (private buildings, industrial) also in collaboration with private companies and Universities;

- energy audits of commercial/industrial facilities in order to design energy efficiency interventions;

- development of simulators in the Matlab/Simulink environment to study the behaviour of smart grid power plants (microturbines, absorption chillers, ...) in steadystate off-design and transient operating conditions;

- experimental tests on cogeneration units and storage batteries in collaboration with plant manufacturers to identify performance maps of components in different operating conditions.

The main peculiarity of the SPM is its nature: it is both an electrical grid and a thermal one. Hence, it provides both electrical and thermal energy to the Campus and, when the Campus electrical load is not so high, it injects electricity into the public distribution network managed by the local Distribution system operators (DSO).

\section{A. The Power Systems of the Smart Polygeneration Microgrid (SPM)}

From the electrical point of view, the SPM is a three-phase low voltage microgrid $(400 \mathrm{~V})$ having a ring configuration. As shown in Figure 2, the following power plants are connected to the SPM, by means of four switchboards in the Campus:

- two photovoltaic fields $(80+15 \mathrm{~kW}$ of peak power) installed on a roof of a building (azimuth equal to $30^{\circ}$ South-East and tilt angle equal to $15^{\circ}$ );

- three cogeneration Concentrating Solar Power systems equipped with Stirling engines (1 electrical $\mathrm{kW}$ and 3 thermal $\mathrm{kW}$ each at rated conditions); 
- three high-efficiency cogeneration microturbines fed by natural gas (one C30 Capstone and two C65 Capstone models);

- a lithium-ions electrical storage systems (composed of 15 batteries, Hitachi CH75-6 type, connected in series and having a total capacity of $25 \mathrm{kWh}$ );

- a sodium-nickel chloride electrical storage system (composed of 6 batteries, ST523 FIAMM SoNick type, connected in parallel and having a total capacity of 141 $\mathrm{kWh}$;

- two EVs charging stations.

Furthermore, the SPM can leverage on two traditional boilers fed by natural gas (450 thermal power each), and on two absorption chillers thermally driven by one of the two C65 microturbines. A thermal network, fed by the hot water produced by the three cogeneration gas turbines and the two gas boilers, is present too; its pipelines are installed underground and properly insulated in order to minimize heat losses.

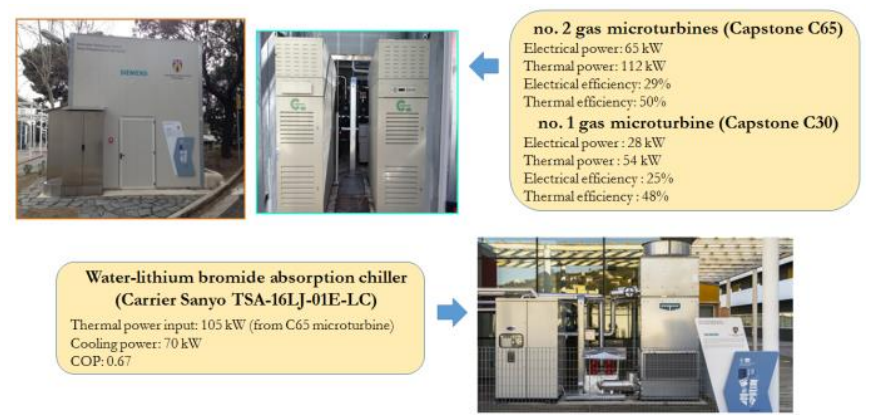

(a)

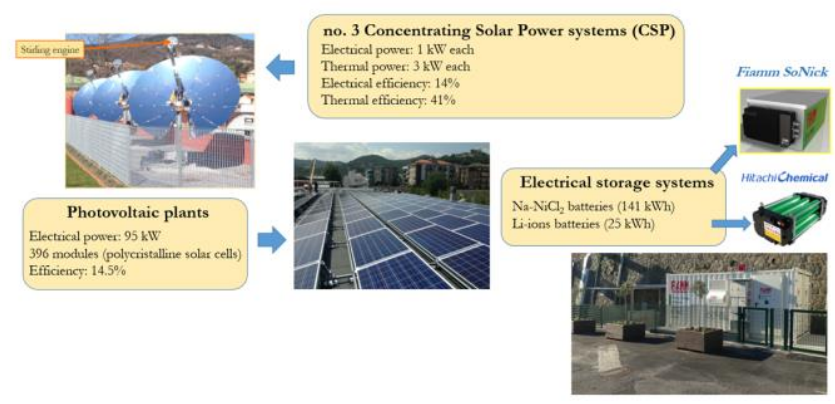

(b)

Figure 2. (a) The trigeneration plants in the SPM and (b) Renewable power plants and storage systems in the SPM.

\section{ENERGY OBTAINED WITH PV SYSTEMS}

The energy production of PV system at SPM was measured every minute during four months, namely January, April, August and November of the year 2015: one month for each season. The goal is to evaluate the energy produced by the PV system installed at SPM for every hour of each day of the four months considered, in order to use such information to perform an electric mobility analysis, which is presented in the rest of the contribution.
In this section, we will investigate the possibility of employing suitable mathematical models in order to reduce the amount of measurements needed for an accurate analysis of the energy production of a PV system, by leveraging on a mathematical energy model which is continuous over time. Hence, starting from the energy production in $\mathrm{kWh}$ measured every fifteen minutes rather than every minute, we compute four suitable polynomial interpolating models with respect to the time, one for each month considered. In particular, we adopt the polynomial interpolation technique pchip [20,21], which preserve the shape and monotonicity of the data. The latter characteristic is important, since the energy produced by a PV system is always a non-negative quantity, minimum zero: the choice of pchip as interpolation technique allows one to preserve this characteristic. More formally, pchip finds values of an underlying interpolant function $P(x) \epsilon C^{1}$ at intermediate points under the constraint that in each subinterval $P(x)$ is the cubic Hermite interpolant, where $C^{1}$ represents the class of functions having the first derivative continuous [20]. Once such interpolating models have been computed, the energy production of the PV system can be evaluated for every minute of the month under study, in order to offer a comparison with respect to the corresponding measurements. Is it possible to see in Fig. 3 that the interpolant models offer a good accuracy and a significant reduction in the amount of measurements necessary to estimate the energy production of the PV system installed in the SPM.
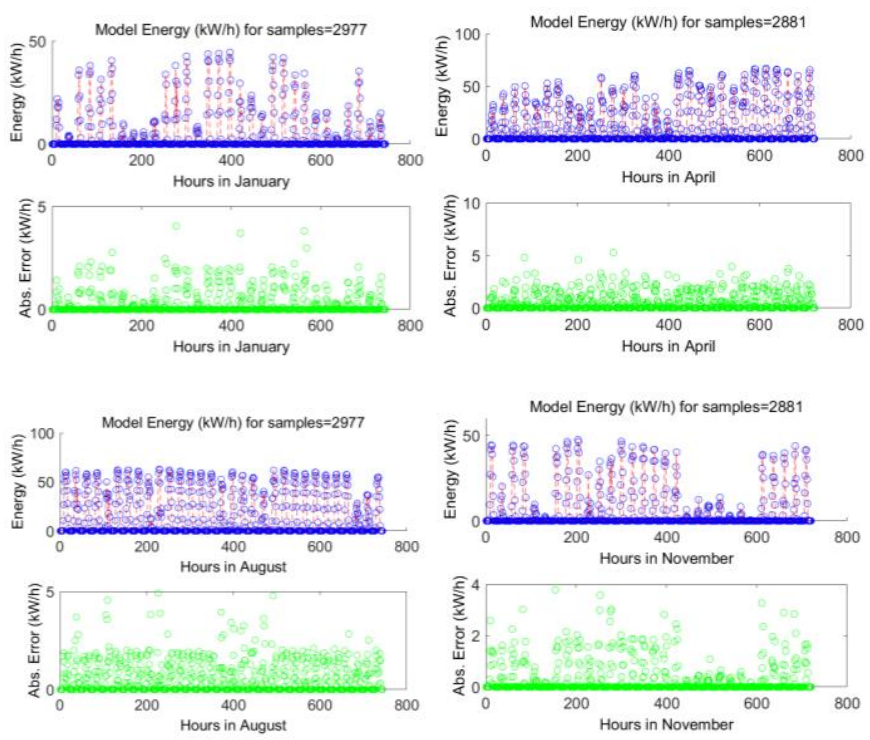

Figure 3. Comparison of the PV energy in different months obtained by measured data (blue circles), the corresponding mathematical model (red dashed line), while the absolute error is indicated with green circles.

\section{ELECTRIC MOBILITY WITHIN THE SMART POLYGENERATION MICROGRID}

In the control room of the SPM it is possible to monitor not only the two charging stations EV-CS1 and EV-CS2, shown on the map reported in Figure 1. However, at the University headquarters in Genoa, there is a third charging station. These 
charging stations owned by the University of Genoa permit to recharge two electric vehicles in use of the University[22-25].

\section{A. Analysis on the Electric Mobility}

In this section, experimental data relative to the two EVs charging stations of the SPM, indicated by CS1 and CS2 are reported and analyzed in detail, referring to the period December 1st, 2014 - November 30th, 2015. Furthermore, data collected on the global irradiance on horizontal plane has been processed using the models described in Section III, in order to estimate the electricity production of a photovoltaic system at the service of the campus.

It is possible to observe the energy produced in different months in Figure 4. It is important to highlight the greater relative variability of the solar radiation during the winter month. This reveals a difficulty in the mobility planning, especially regarding the use of green energy for the vehicle charging. In this case, experimental data have been considered as well of the CS located at the University of Genoa because all the three CSs are monitored from the control room of the Smart Polygeneration Microgrid.
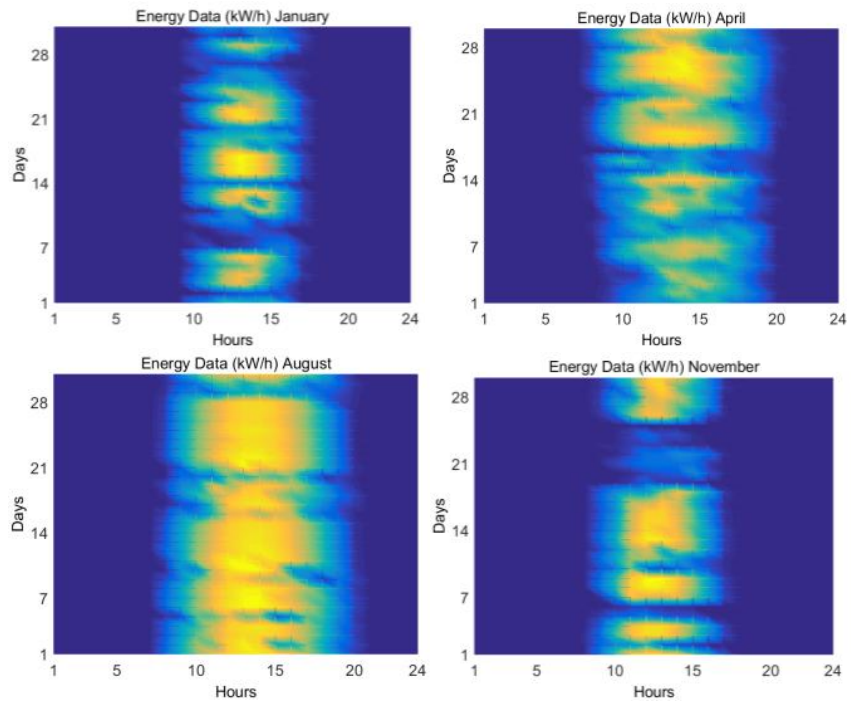

Figure 4. Energy produced by the PV systems installed in the SPM.

In Figure 5 two typical charging profiles are reported for the Twizy and the Fluence, in terms of power and energy charged as a function of not normalized time. In particular, the plotted data refer to the charging of the Twizy from $40 \%$ to $100 \%$ of the SOC (State Of Charge), whereas the Fluence data are relative to a charging from $53 \%$ to $100 \%$ of the SOC.

Table 1 shows three different time slots, identified respectively with the names F1, F2 and F3 as a function of the day and the hour in which the Electric Vehicles are recharged.

Each time slot is characterized by different prices of electricity. During the time slot F1, it is convenient to charge EVs by means of the electricity produced by the SPM because, in this case, the PV plant produces higher energy. A different situation is for nighttime slots when the EVs are charged by withdrawing electricity from the public grid or from the storage systems of the smart grid.

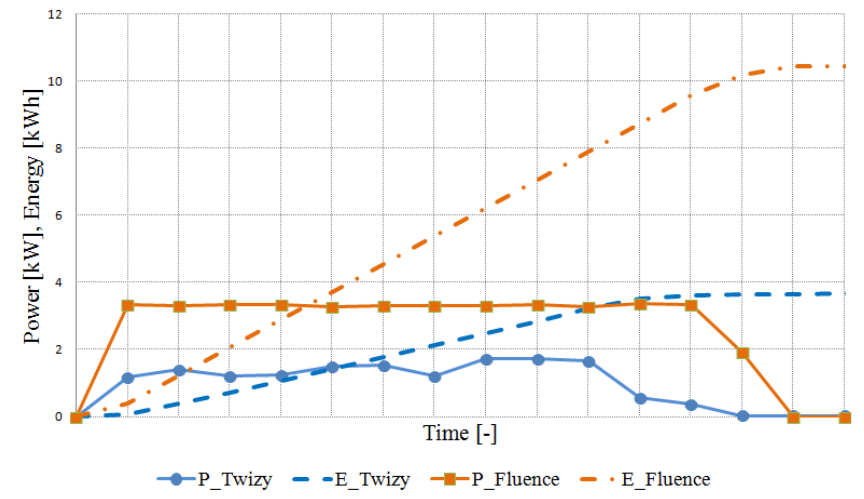

Figure 5. Power and energy charging profiles of the two EVs considered.

Table I: Different time slots for EVs charging

\begin{tabular}{|l|c|c|c|}
\hline & $\begin{array}{c}\text { From Monday to } \\
\text { Friday }\end{array}$ & Saturday & Sunday and feast day \\
\hline From 7 a.m. to 8 a.m. & F2 & F2 & F3 \\
\hline From 8 a.m. to 7 p.m. & F1 & F2 & F3 \\
\hline From 7 p.m. to 11 p.m. & F2 & F2 & F3 \\
\hline From 11 p.m. to 7 a.m. & F3 & F3 & F3 \\
\hline
\end{tabular}

Some specific "key performance indicators" (charged energy, the recharge time and the time slot used) have been identified during the EVs charging infrastructure's experimental compaign [16].

To better understand the habits of the EVs's users, other variables as charged energy, minimum and maximum values that can occur and the most probable variation range have been evaluated.

Figure 6 and 7 show for the different sites (Savona and Genoa) the energy drawn for each charge and the charging time for the examined CSs. Observing these graphs, it is possible to observe that the Renault Twizy is recharged in Savona whereas the Renault Fluence Z.E is recharged in Genoa. In particular, in the Savona Campus, the recharges are characterized by $4 \mathrm{kWh}$ on average and 2.5 hours whereas, in the University of Genoa, the values of recharge are respectively $12 \mathrm{kWh}$ and 4 hours. Another aspect that has emerged from the data analysis is the different habits for the vehicles recharge. It is possible to observe that the EVs located in the different sites have been used according to the real needs of the endusers. A good opportunity is to use the EVs as electrical storage systems, following a Vehicle-to-grid (V2G) strategy [26, 27]. In the future, the research activity will be also focused on the V2G option, since a V2G charging station is going to be installed at the Savona Campus.

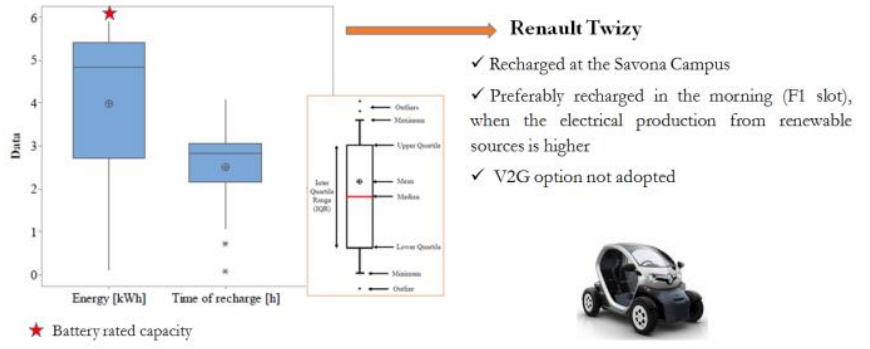


Figure 6. Data analysis for the Renault Twizy charging in Savona.

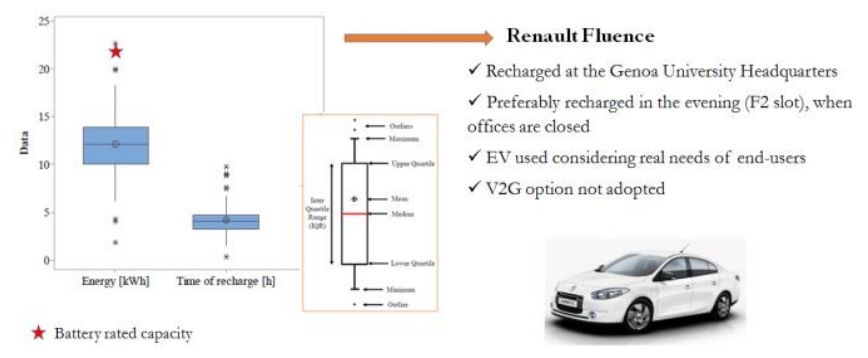

Figure 7. Data analysis for the Renault Fluence charging in Genoa.

\section{CONCLUSIONS}

Electric mobility, also called e-mobility, represents a key challenge for the sustainable mobility of the future. Different powertrain technologies are available on the market, such as full electric or hybrid vehicles, and it is expected that their capital cost and performance features (mainly charging time and driving range) will be more and more attractive in the next years. Electric vehicles can be a valid alternative for fleets adopted by public administrations and in the tertiary sector, in order to reduce primary energy consumptions, fuel costs and carbon dioxide emissions. Moreover, the role of the e-mobility in the distributed generation scenario is also notable, where innovative electric vehicles can be seen as flexible small size storage systems useful to compensate the fluctuating production of photovoltaic and wind power plants. In the present paper the aforesaid aspects have been highlighted by focusing on the role of electric vehicles within microgrids. The pilot case of the Savona Campus in Italy is described and some interesting results of the analysis conducted on electric vehicles are reported.

\section{REFERENCES}

[1] https://ec.europa.eu/jrc/en/research-topic/transport-sector-economicanalysis

[2] European Commission, "Fact-finding studies in support of the development of an EU strategy for freight transport logistics - Lot 1: Analysis of the EU logistics sector," January 2015.

[3] ERTRAC/EPoSS/SmartGrids, "European Roadmap Electrification of Road Transport," 3rd Edition, 2017.

[4] European Commission, "Transport," November 2014 (Available at: https://europa.eu/european-union/topics/transport_en).

[5] Amsterdam Roundtable Foundation and McKinsey \& Company The Netherlands, "EVolution - Electric Vehicles in Europe: gearing up for a new phase?," April 2014.

[6] S. Kuppusamy, M.J. Magazine, and U. Rao, "Electric vehicle adoption decisions in a fleet environment," European Journal of Operational Research, vol. 262, pp. 123-135, 2017.

[7] European Union, "EVUE: Electric Vehicles in Urban Europe", available http://urbact.eu/sites/default/files/import/Projects/EVUE/documents_m edia/EVUE_report_280912_FINAL.pdf.

[8] C. Thiel, J. Krause, and P. Dilara, "Electric vehicles in the EU from 2010 to 2014 - is full scale commercialization near?," JRC Science and Policy Report, 2015.

[9] K. Kieckhafer, K. Wachter, and T.S. Spengler, "Analyzing manufacturers' impact on green products' market diffusion - the case of electric vehicles," Journal of Cleaner Production, vol. 162, pp. S11S25, 2017.
[10] J. Buekers, M. Van Holderbeke, J. Bierkens, and L. Int Panis, "Health and environmental benefits related to electric vehicle introduction in EU countries," Transportation Research Part D, vol. 33, pp. 26-38, 2014.

[11] J.C. Gonzalez Palencia, Y. Otsuka, M. Araki, and S. Shiga, "Scenario analysis of lightweight and electric-drive vehicle market penetration in the long-term and impact on the light-duty vehicle fleet," Applied Energy, 2017.

[12] I. Vassileva, and J. Campillo, "Adoption barriers for electric vehicles: experiences from early adopters in Sweden," Energy, vol. 120, pp. 632641, 2017.

[13] J. Riesz, C. Sotiriadis, D. Ambach, and S. Donovan, "Quantifying the costs of a rapid transition to electric vehicles," Applied Energy, vol. 180, pp. 287-300, 2016.

[14] M. Mruzek, I. Gajdac, L. Kucera, and T. Gajdosik, "The possibilities of increasing the electric vehicle range," Procedia Engineering, vol. 192, pp. 621-625, 2017.

[15] M. Strehler, S. Merting, and C. Schwan, "Energy-efficient shortest routes for electric and hybrid vehicles," Transportation Research Part B, vol. 103, pp. 111-135, 2017.

[16] S. Bracco, M. Brenna, F. Delfino, F. Foiadelli, M. Longo, "Sustainable Electric Mobility Analysis in the Savona Campus of the University of Genoa", In Proceedings of 16th International Conference on Environment and Electrical Engineering (EEEIC 2016), Firenze, 7-10 June 2016.

[17] V.N. Coelho, I.M. Coelho, P.J. Fleming, et al., "Multi-objective energy storage power dispatching using plug-in vehicles in a smartmicrogrid," Renewable Energy, vol. 89, pp. 730-742, 2016.

[18] A.K. Basu, S.P. Chowdhury, S. Chowdhury, and S. Paul, "Microgrids research: A review of experimental microgrids and test systems," Renewable and Sustainable Energy Reviews, vol. 15 (2011), pp.43484356.

[19] H. Kamankesh, V.G. Agelidis, A. Kavousi-Fard, "Optimal scheduling of renewable micro-grids considering plug-in hybrid electric vehicle charging demand," Energy, vol. 100, pp. 285-297, 2016.

[20] F.N. Fritsch and R.E. Carlson, "Monotone Piecewise Cubic Interpolation", SIAM Journal on Numerical Analysis, 17:238-246, November 1980.

[21] D. Spina, F. Ferranti, G. Antonini, T. Dhaene, L. Knockaert and D. Vande Ginste, "Time-Domain Green's Function-Based Parametric Sensitivity Analysis of Multiconductor Transmission Lines," IEEE Transactions on Components, Packaging and Manufacturing Technology, vol. 2, no. 9, pp. 1510-1517, September 2012.

[22] Z. J. Ma, D. Callaway, and I. Hiskens, "Decentralized charging control for large populations of plug-in electric vehicles: Application of the Nash certainty equivalence principle," in Proc. IEEE Int. Conf. Control Appl., Sep. 2010, pp. 191-195.

[23] E. Sortomme and M. A. El-Sharkawi, "Optimal charging strategies for unidirectional vehicle-to-grid," IEEE Trans. Smart Grid, vol. 2, no. 1, pp. 131-138, Mar. 2011.

[24] M. Ceraolo, A. di Donato, G. Franceschi: "A General Approach to Energy Optimization of Hybrid Electric Vehicles", IEEE Transactions on Vehicular Technology, May 2008, Vol. 57, N. 3, pp. 1433-1441.

[25] A. Dolara, G. C. Lazaroiu, S. Leva, and G. Manzolini, "Experimental investigation of partial shading scenarios on PV (photovoltaic) modules," Energy , vol. 55, no. 15, pp. 466-475, 2013.

[26] T.U. Daim, X. Wang, K. Cowan, T. Shott, "Technology roadmap for smart electric vehicle-to-grid (V2G) of residential chargers", Journal of Innovation and Entrepreneurship (2016) 5:15.

[27] F. Samweber, S. Fischhaber, P. Nobis, "Electric mobility as a functional energy storage in comparison to on-site storage systems for grid integration”, Energy Procedia, vol. 73, pp. 94-102, 2015. 